\title{
Grignon
}

LA CUL TURE DL GINSENG

U d' $/$ of Ottawa

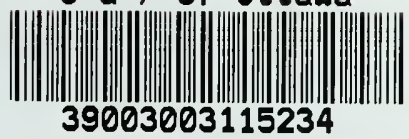

295

. G5G7 1907 



\section{La Culture}

\section{DU \\ Ginseng}

Traité complet et illustré PAR

Dr W. GRIGNON, M. C.A. Shinte-Adele, Que.

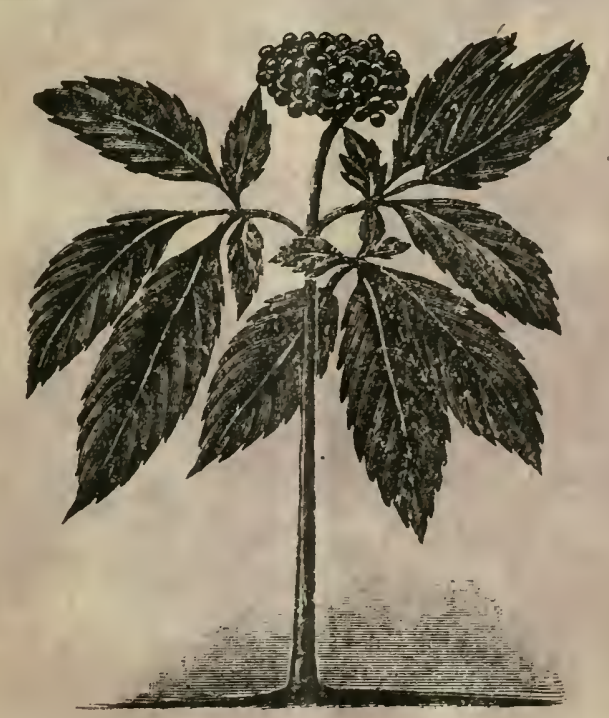

(Fig. 1)

TIGE DE GINSENG

En vente chez

DR. W. GRIGNON,

STE-ADELE, QUe. 



\section{La Culture}

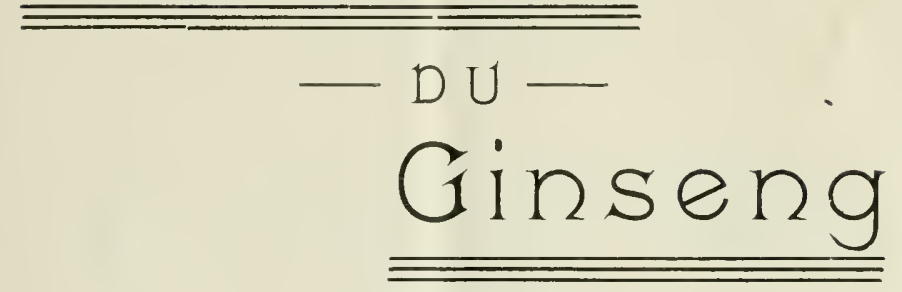

Traité complet et illustré

PAR

Dr W. GRIGNON, M. C.A.

Shinte-Adele. Que.

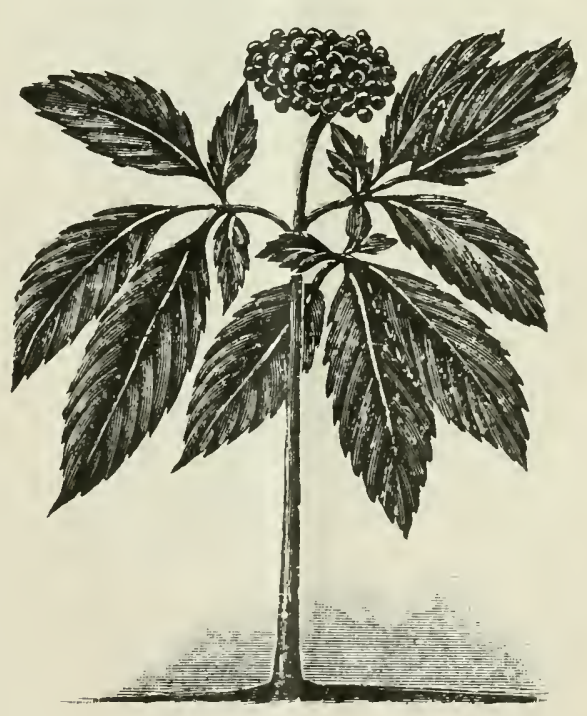

(Fig. 1)

TIGE DE GINSENG

En vente chez

DR. W. GRIGNON.

STE-ADELE, QUe. 
Digitized by the Internet Archive in 2010 with funding from University of Ottawa 


\section{LE}

GINSENG

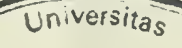

BIBLIOTHECA

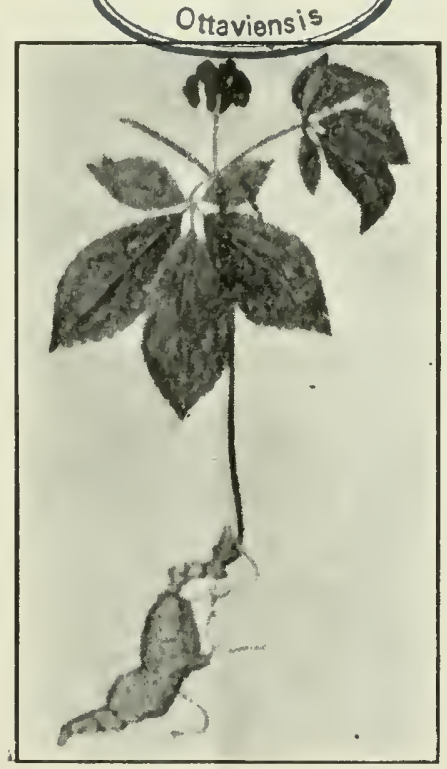

(Fig. 2)

TIGE ET RACINE DE GINSENG 
Einregistré conformément à l'acte du Parlement dn Canarla, en l'annce mil neuf cent sept, par WILFRII) GRIGNON, an bureau du Ministre de l'Agriculture à Ottawa.

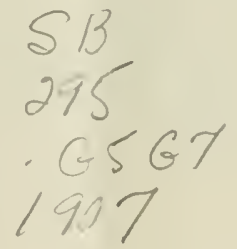




\section{Introduction}

Je n'ai jamais en l'intention, en faisant cette petite brochure, de chauffer à blanc l'enthousiasme des cultivateurs au pount de les voir convertir leurs fermes en jardins à Ginseng. Non! ! il ne faut pas s'exciter à ce point-là. Rappelons-notis de la course endiablée de isgs vers le Klondyke d'où plusieurs chercheurs d'or sont revenus plus pauvres qu'avant et où même plusieurs sont morts dans la mendicité. Peut-être en serait-il de même de la culture du Ginseng si on y mettait autant d'entrain; on n'y risquerait pas sa vie, mais on y risquerait son temps et son argent. Il n'en est pas moins vrai cependant que plusieurs de nos amis du Klondyke sont revenus avec de jolies petites fortunes qu'on ne saurait attribuer seulement au hasard mais aussi à un travail persévérant.

La culture du Ginseng n'offre pas autant de risques que la recherche de l'or dans les mines, mais les succès sont infiniment plus certains si l'on se conforme aux conditions exigées.

Les conditions de succès se résument à :

I. Le choix, le site du terrain ct la nature du sol ;

2. L'achat de bonnes graines stratifićes éprouvées à l'ean et récoltées dans notre payss et non à l'étranger ;

3. L'cntrction et les soins de culture de cette plante;

4. La priparation des racines pour le marché ;

5. Le choir d'acheteurs conscicncienx et non d'exploiteurs.

Il est constaté, calculé et hors de tout doute que le Ginseng bien cultivé peut rapporter, en ınoins de $\tau$ ans, non pas $\$ 50.00$ mais bien

\section{\$5O,OOO PAR ARPEN'T}

Un chiffre aussi éloquent est bien de nature à soulerer l'enthousiasme de certaines gens au point de les engager à mettre $\$ 2,000$ ou $\$ 3$, ooo du coup dans cette culture.

Ce serait plus que de la témérité, ce serait de la folie. 
Non! il ne fant pas aller aussi vite que cela, et c'est pour brider ces élans passagers que $\mathrm{j}$ 'ai fait ce livre.

Qu'un homme consacre $\$ 5.00$ à l'achat de 100 graines de semence, où \$I 5.00 pour l'achat de 500 graines, out même \$25.00 pour l'achat de rooo graines, le risque 11'entraîne pas la ruine, mais, tout de même, ce risque ne sera pas à redouter, si l'on suit attentivement les conseils de mon petit traité, et c'est pour cela que je l'ai fait, afin qu'il vous serve de guide, de boussole dans cette culture, qui est, après tout, très aisée, et très payante.

- Je crois que mon livre est le premier écrit en langue française sur ce sujet, ici et à l'étranger ; du moins, je ne trouve rien dans les catalogues qui indique qu'il en existe d'autres. C'est déjà un mérite.

Il aurait pu être écrit en meilleur français, je l'avone, unais à ceux-là qui attachent plus d'importance à la forme, au style qu'au fond, je leur dirai qu'ils sont libres de faire mienx.

Je ne connais sur ce snjet, la culture du Ginseng, que des livres Américains. Mais je m'empresse de vons dire que je n'ai eu recours à aucun de ces livres. D'un autre côté, je ne puis m'attribuer le mérite de cet ouvrage, que je n'aurais jamais entrepris sans les conseils de denx amis, qui cultirent le Ginseng dans la prorince de Québec arec un grand succès, mais dans le silence, et tellement dans le silence qu'ils n'ont pas même voulu que je les nomme dans mon livre, ce que je voulais faire par reconnaissance. Ils sont vraiment trop modestes. Tout de même

- ils ne sont pas avares de leurs connaissances car ils se sont laissés pomper à mon gré.

Je connais un médecin, pas loin d'ici, qui est sans clientèle et qui vit comme un seigneur. La sonrce de ses rerenus était un mystère pour tout le monde. Un amateur de Ginseng passant par là un jour remarqua quelques carrés de Ginseng dans son jardin. "Mais, Docteur, lui dit cet étranger, rous derez. faire de l'argent avec cette culture" ! "Chut! Chut! lui répondit le Docteur, c'est la. senle source de mes revenus, et je vis comme un paclia. Je ne veux pas le dire aux gens de crainte qu'ils se mettent à en cultiver et ça me ferait de la compétition." L'étranger partit d'un formidable éclat de rire, en voyant les craintes puériles du bon Doctenr qui ignorait que le marché est illimité.

Loin de là, plus nous en cultiverons plus nous trouverons à le vendre. 
Croyez-vous, par exemple, que s'il n'y avait daus notre pays que roo beurreries, elles rendraient leur beurre plus cher en Angleterre? Pas du tout. Mais en w1ettant sur le marclié anglais de grandes quantités de beurre et de fromage, on a éreillé l'attention des consommateurs qui se dirigent maintenant de notre côté et on a créé nu marché important. Eh bien ! il en sera de même du Ginseng. Le jour oì chaque cultivateur aura son petit jardin de Ginseng et oì le Canada pourra fournir annuellenent de grandes quantités de cette racine, les Chinois se dirigeront de notre còté et on aura un excellent marché de Ginseng comme on a un excellent marché de beurre et de fromage.

Jusqu'ici on a cultivé le Ginseng dans l'ombre, le silence et le secret. Voyez, par exemple, les chercheurs de racines conme ils sont mystérienx; ils sont réservés, discrets comme des francs-maçons. Il en vient ici, à Ste-Adèle. tous les ans, depuis 20 ans, parcourant les bois en tous sens et qui s'en retournent avec 2 ou 3 poches de cette racine. L'un de ces chercheurs, un peu émêché, parlant trop fort, fut surpris par la maitresse de la maison, à rliscuter sur la valeur des deux poches de racines qu'ils araient cueillies sur la terre de cette femme et les terres roisines, dans l'espace de 8 jours. Il affirmait que leurs produits valaient an moins \$IOOO, tandis que l'autre affirmait qu'ils ralaient au moins \$I200. Dans la nuit, la femme vola une racine et me raconta le lendemain dans le silence, avec prière d'en garder le secret, la conversation des deux étrangers, puis me nontra la racine qui était ni plus ni moins qu'une belle racine de Ginseng.

Pas hesoin de vons dire qu'elle attend ces étrangers arec u11 bea1ı inanclie à balai.

Quaut à 1110i, il n'y a pas de danger que j'en parle, je suis si discret !! Mais, par exemple, je vais l'écrire.

Il est temps de rompre le silence et de déchirer le voile nyystérieux qui a caché jusqu'ici les trésors que contiennent nos belles forêts de bois franc et qui sont également réservés à ceux qui ferout la culture artificielle de cette plante arec intelligence.

Grâce aux gravures de mon livre il vous sera assez facile de trouver le Ginseng dans les bois.

Quant à ceux qui ont remplacé la forêt par de beaux champs cultivés, ils pourrout facilenent faire revirre la culture du Ginseng, par la culture artificielle, sur wu espace cle terrain très restreint. 
Il ue fant pas oublier que cette culture exige très pen de terrain. C'est pourquoi elle convient bien, non seulement à tous ceux qui possèdent de grandes fermes, mais elle convient également à quiconqie possède un jardin ordinaire, comme on en remarque chez les curés, les communautés religieuses, les hommes de professions libérales, les marchands, les industriels, etc., etc. En un mot, elle convient à tout le monde.

"Que tout canadien ait un petit coin de son jardin en Ginseng." Tel est le but de ce petit livre.

Maintenant mettons-nous à l'œurre et lançons-nous dans le Ginseng !

\section{Dr W. GRIGNON.}

STE-ADÉLE. Qứ

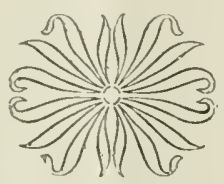



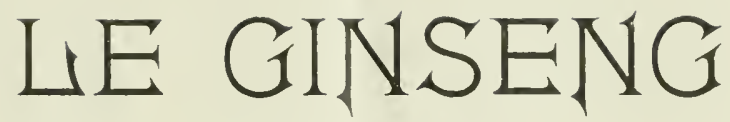

$\mathrm{O}=0$

\section{DESCRIPTION BOTANIQUE}

Ginseng -Panax. Pan (tout) Alkos (remède), c'està-dire remède à tous les maux.

Fleurs polyganes. Calice à limbe obscurément 5 denté. Corolle à 5 pétales étoles. Etamines 5, à filets courts, alternant arec les pétales. Styles 2-3, divergents. Baies à 2-3 loges monospermes. Herbes ou Arbrisseaux. Feuilles 3 dans les espèces herbacées, composées. Fleurs en ombrelles solitaires simples.

Ginseng à trois feuilles. Panax trifolium.-Panax pusilla.-Aralia triphylla.-Ground-nut.-Dwarf Ginseng. Tivace.-Tige glabre, grêle, simple, de 8 à 9 pouces de haut très tendre. Feuilles groupées circulairement autour de la tige à 3-5 folioles à peu près glabres, lancéolées, dentées, subsessiles. Styles 3. Baie à 3 graines. Fleurs mâles et femelles sur des plantes différentes, ces dernières sans étamines, suivies de baies de conleur verte, les premières avec un style abortif. Racine profondément enfoncée dans le sol, globuleuse, d'environ 1/2 pouce de diamètre se joignant à la tige par un ligament en spirale.

Pédicule solitaire, sortant du centre des 3 feuilles et portant nne petite ombrelle de fleurs d'un blanc pur; Canada-Floride, bois, sur les bords humides des ruisseaux.

Ginseng à cinq fenilles. Panax quinque folium-Ginseng-Grand Ginseng-Ginseng.-Vivace-Tige cylindrique, glabre, de 15 à is pouces de haut, terminée par un rerticelle de 3 feuilles, composées et un pédicule central portant une ombrelle simple. Feuilles à 5 folioles ovales, acuminées, dentées, pétiolulées. Pédencule plus court que les pétioles. Fleurs petites, jaunâtres, portées sur des pédicolles courts : les fleurs mâles et femelles sur différents individus, ces dernières suivies de baies d'un rouge brillant. Croît au Canada, à la Caroline, dans les terrains riches, dans les terres de bois franc surtout, etc., etc. 


\section{DESCRIPTION POPULAIRE}

La tige du Ginseng qui a I 2 à 15 pouces de longueur, se partage au sommet en trois branches de 3 à $3 \frac{1}{2}$ pouces de longueur ; à chaque extrémité sont disposées 5 folioles minces, lisses, d'une structure délicate ; dans chaque groupe de foliole, deux ont environ deux pouces de long et les trois autres presque quatre pouces; ces folioles sont de forme ovale, mais allongées en pointe et sont dentées sur les bords.

An centre des trois fenilles composées et en prolongement de la tige principale, il $y$ a tune simple tige à fleurs de 3 pouces de long et portant des fleurs peu apparentes, blanc verdâtre, qui rappellent une petite tête de trèfle blanc. (Fig. I, page I, Fïig. 2, p. 3).

La présence d'une tige à flour unique est importante, car elle sert à distinguer la plante d'une autre espèce de Ginseng qui possède + tiges florales. mais constitue une varıété tout-à-fait distincte, quoiqu'appartenant au même groupe.

Grâce aux caractères ci-dessus décrits et à la gravure qui figure sur le livre "Tige de Ginseng," le lecten1pourra aisément reconnaître la vraie plante et la distinguer d'autres plantes qui lui ressemblent.

La racine a ia forme de carottes, panais, etc., elle est grande, fusiforme, souvent fourclue, longue de + à 9 pouces.

\section{PROPRIÉTÉS MÉDICALES}

Racine fusiforme, blanchâtre, charmue, aromatique, stimulante, tonique, etc. Cette plante considérée comme nne panacée en Chine s'y vend au poids de l'or.

Elle est un tonique stimulant des plus puissants, surtout pour relever les forces abattues par les excès et stimuler la digestion. Quelques personnes ont l'habitude de mâcher cette racine par goût.

Dose. 1/2once de racine dans une chopine d'ean ou de vin dont on prend un verre à vin avant les repas.

Les Clinois en portent continnellenent sur eux quand ils peurent en acheter. Le Chinois s'innagine que cette plante le préserve contre toutes les maladies et prolonge sa vie.

Un voyageur en Cline rapporte qu'il n'est janais entré che\% un droguiste sans roir vendre du Ginseng. Les médecins clinois affirnent que le Ginseng ranime les for- 
ces dans les cas d'extrême fatigue, rend la respiration plus facile, fortifie l'estomac, provoque l'appétit, guérit les affections nerveuses et donne de la vigueur au corps, même dans unl âge très avancé.

Je connais un conseiller législatif de Montréal qui attribue sa vigueur et sa bonne santé à l'nsage quotidien de cette racine, qu'il gruge arec antant de délice qu'un rat d'église grugerait un pain bénit.

Après tout, on a eu tort pent-être d'aroir substitué aux plantes sauvages, aux végétaux des substances minérales à principes concentrés, dont l'action toujours violente peut devenir très nuisible ou même fatale dans une application incertaine on mal dirigée. Qui sait, clit l'abbé Provencher, si dans quelques années la science d'Essculape, après un grand détour, n'en reviendra pas à son point de départ, nous voulons dire à la médecine des simples, pour mieux atteindre son but? Du moins, c'est vers ce point que tendent anjourd'hui quelques esprits sérienx en Europe et en Amérique, et les heureuses combinaisons des deux systèmes de médications employés par eux ont déjà eu les résultats les plus satisfaisants.

La racine de Ginseng est jaune à l'intérieur, sa cassure est plus ou moins blanche ou farineuse; son odeur peu prononcée, rappelle celle de l'Angélique ; sa savcur anère et sicrée, excite la salivation.

\section{HISTOIRE - ORIGINE - VALEUR}

C'est le Père Lafiteau, missionnaire Jésıite chez les Iroquois, qui, le premier, découvrit le Ginseng en Canada près de Montréal, en l'année 17 I6 ; en I7ı 8 il en fit connaître l'importance. Immédiatement les Canadiens-Français se mirent à le recueillir et à l'exporter en Chine, et cette exportation devint si importante qu'elle donna pour plusieurs années une grande importance au commerce de Montréal. A cette époque on engagea un grand nombre d'Indiens pour en faire la récolte aux environs de Montréal et de Québec et on en expédia de grandes quantités ell Chine..

Il est regrettable qu'alors on ait négligé la préparation de la racine et l'empaquetage en vue du marché.

En I 832 les enrois de Ginseng des Eitats-Unis atteignirent le chiffre de 407,067 livres d'une valeur de $\$ 99,303$. Dans un comté du Wisconsin on en expédia pour $\$ 40,000$ en 1858 et pour $\$ 80,000$ en 1859 . 
Le Minnesota en a exporté d'immenses quantités. Actuellement, les principales sources de production sont les Eitats d'Ohio, de Virginie Onest et de Ninnesota.

Vers la fin du r 8ène siècle, le Ginseng fut anssi découvert dans le Massachusetts et son exportation donna de gros bénéfices. En IS90, l'exportation des Etats-Tnis fut de 75,000 livres.

Dans les forêts de la Tartarie, on en trouvait jadis en abondance : cette plante est presque disparue ; c'est pour cette raison qu'on s'est adressé à l'Amérique pour en aroir.

\section{MARCHÉ, ILLIMITÉ}

La quantité de Ginseng exporté du Canada en I 890 représente la somme de $\$$ I00,000, et un seul droguiste en a exporté pour \$1,600. Lra région qui s'étend le long de la ligne du chemin de fer Kingston et Pembrooke en a fourni pour $\$ 20,000$.

Le Consul Américain à Amoy sur la Côte de Chine écrivait à son gouvernement en $18 g S$ : "Je ne crois pas me tromper en disant qu'il y aurait moyen de vendre ici annnellement au-delà de $\$ 20,000,000$ de racines de Ginseng : les importateurs chiuois réalisent des fortunes arec ce produit. Le Ginseng ressemble fortement au raifort (lorse radish). L'espèce à 5 feuilles est celle qu'il faut pour l'exportation. En Chine tont le monde achète cette panacée universelle, jusgu'an plus paurre paysan qui économise péniblenent pour en acheter une on deux lives par an."

\section{CLASSIFICATION}

I.es Ginsengs les plus fins sont cenx que l'on cultive en Chine, où le Gouvernement en a le contrôle et le mono. pole. Quiconque anrait la hardiesse, la témérité d'endommager ou de voler cette plante, serait mis à mort sur le champ comme un exécrable scélérat

Les Ginsengs cultivés dans les jardins impérianx ne sont jamais livrés à la consommation arant l'âge de 75 ans. Il n'y a que les gens fortunés on appartenant au cercle de l'aristocratie qui font usage de ce cinseng extrafin.

A 75 ans, il vaut $\$ 100$ la livre sèche, à 100 ans \$I 50 et les racines de choix valent jusciu'à \$200 la livre.

La deuxième classe comprend le Ginseng du Mexique 
qui raut $\$ 35.00$ la livre sèclıe. Les inunenses forêts de ce pays counule celles des autres Eitats ont été arpentées, parcourues en tous sens et aujourd'luui cette plante est à peu près épuisée. Les Mexicains ne cultivent pas le Ginseng.

I a troisième classe comprend le Ginseng du Canada. L,e Ginseng sauvage vaut 5,6, 7 et même $\$ 8.50$, selon sa grosseur et sa qualité.

Les racines trop petites ou trop jeunes n'ont pas la même valeur aux yeux de l'acheteur chinois.

Il y a 3 ans ( I904), les arracheurs de Saint-Joseph, Co. des Deux-Montagnes, ont vendu $\$ 7.00$ la livre sèche.

L'an dernier, ils n'ont vendu que $\$ 6$.0o parce que les racines contenaient trop d'eau; d'autres n'ont vendu que $\$ 4.50$ la livre parce que la racine avait le goût de brûlé, ayant séché trop rapidement à la chaleur intense du four.

Il y a 2 ans, me dit un de mes amis qui cultive le Ginseng, des américains m'ont écrit qu'ils paieraient le Ginseng canadien $\$ 8.50$ la livre sèche.

La quatrième classe comprend les Ginsengs de l'Anéri. que du Sud qui se vendent généralement $\$ 2.50$ à $\$ 3.00$ la jivre. Est-ce à cause du climat ou de la nature du sol, ce point n'a pas encore été éclairci. Dans tous les cas le marché est illimité, et si la Clhine n'en achète que \$I,000,000 c'est parce qu'il n'y en a pas plus.

Miss I. IV. Roberts a dit récemment devant l'Académile des Sciences, à Syracuse, qu'il y a devant eux un marché d'au-clelà de $\$ 30,000$, o0o et pour encourager le cultivateur à se livrer à cette iudustrie, elle citait M. L. Ready qui a vendı en novembre dernier 1906, 224 livres de Ginseng cultivé $\$ 2,240$, soit $\$ 10.00$ la livre, à part 50 livres de graines de semence à $\$ 5.00$ l'once, soit $\$$ \$. OOO de graines.

Iin 1900 un fermier du Missonri a vendu du Ginseng cultivé pour le joli n10ntant de $\$ 25$,000 récolté sur $1 / 2$ arpent à peine, ce qui nous prouve bien la haute valeur du Ginseng cultiré.

\section{CAUSES D'INSUCCËS}

Si les acheteurs offrent moins que $\$ 7.00$ la livre, la faute en est à certains cultivateurs débutants dans cette culture, qui n'ont pas su donner à la plante les soins roulus, qui ont appliqué du fumier de ferme à des doses exagérées, ou qui ont arrosé leur plantation avec dı purin d'étable. ou qui, à l'autonne, au lieu de couvrir leur culture avec 
Tes femilles comme on doit le faire pour protéger la plante contre les froids d'hiver, ont commis la maladresse de se servir de fumier frais de cheval. Durant 7 ans, ils ont accunulé à tous les automues 3 ou + pouces de crottin de cheval. Après une méthode aussi défectueuse, aussi pen rationnelle, est-il étonnant de voir les habitants du Céłeste Empire apprécier si pen le Ginseng de l'Anérique du Nord.

D.autres ont négligé l'empaquetage et n'ont pas pris Hes précautions roulues pour faire sécher les racines. II faut bien peu de produits de qualité inférieure pour nuire. à la rente des bons produits. Quant à mettre du Ginseng sur le marché, produisons-le dans les conditions exigées par le consommateur ou ne nous en mêlons pas. C'est f'un ou l'autre, un bon produit ou rien du tout. La cliose est aisée d'ailleurs, alors pourquoi se le ferions-nous pas?

\section{LA CULTURE ARTIFICIELLE DU GINSENG}

\section{E'T}

\section{LE GINSENG DE LA FORE'T}

Est-il préférable de cultiver le Ginseng au lieu de récolter le Ginseng naturel de la forêt? Lequel des deux a le plus de valeur? Telle est la question qui m'a été posée bien souvent. Il n'y a pitus de doute là-dessus. Le Ginseng cultivé est infiniment préférable. Telle est la réponse qui m'a été donnée par un aıni qui a bien voulu me donner des conseils et voici ce qu'il dit à ce propos : " M. Arthur Thompson me dit d'avoir appris verbalenent d'un médecin chinois que les racines ctrltirées et arracliées à $\&$ ans d'âge étaient de beaucoup plus estimées que les racines sauvages : leur uniformité en grosseur. leur belle couleur blanche captive l'acheteur ". Il est reconnu que les racines cultivées donnent un brenvage bien supérieur à celui provenant des racines sauvages et qu'elles contiennent des propriétés mérlicales plus mombreuses et plus efficaces.

N'en est-il pas ainsi de nos arbres fruitiers? I,es fruits délicienx de nos verogers ne sont-ils pas d'origine satuvage?

I, 'homme a arraché sh sol sanvage et souvent ingrat les pommiers samrages, les a transpłantés avec symétrie daus une terre fortile et ljien préparée, les a taillés avec soin, les a greffés. Quels en ont été les résultats? C"est 
qu'ou a anjourd'hui des fruits en abondance et d'une saveur délicieuse, au lieu d'avoir pen de fruits et d'un goût désagréable.

Faisons de mê:ue pour le Ginseng ; arrachons-le de la forêt, sortons-le de son état sauvage pour le civiliser, transplantons-le dans une terre bien riche et bien travaillée, adoptons un systême de culture rationnelle et nous verrous ces racines non seulement doubler en valenr, mais centupler en quantité et en qualité.

" Mais cette transplantation de racines sauvages, we lisait mon ami, exige du temps et de la patience. Il est infuniment préférable à tous les points de vie, de se procurer de la graine de Ginseng stratifiée et épronvée à l'ean, récoltée dans la province de Québec on des jeunes plants l'un an de notre pays que de courir les bois après les racines saurages, si on veut mettre sur le marché un produit de meilleure qualité.

\section{NATURE, DU SOL_OU CUI,TIVER LE, GIN- SENG}

\section{PRÉPARATION DE SOI,}

Le terrain destiné à cette culture doit être aussi riclıe que celui d'mu jardin potager. Les engrais doivent être déjà bien déconnposés (l'arance et bien assimilés, c'est-àdire an moins $n 11$ an d'avance, ayant produit nne récolte de légumes.

Ce terrain derra être cléfoncé profondément ( $1 / 2$ à 2 pieds), et si le sons-sol n'est pas parfaitement perméable, il derra être drainé au moyen de drains sous terre plus rapprochés que pour tn drainage ordinaire, par exemple, I 5 à 20 pieds entre les lignes des drains.

Les seuls engrais subséquents ne doivent êtres que cendres de bois, terreaux de forêt et feuilles de forêt.

Le Ginseng ne croit pas sous les cerisiers, bouleaux, trembles et sapins, mais il se plaît sous les pommiers, les noyers tendres, l'érable et le bois blanc. Donc l'on pent en déduire quel'on ne devrait se procurer ces terreanx de feuilles que dans les forêts oì l'on trouve ses espèces de feuilles.

Il est nécessaire la première année d'enfouir ce terrean avec les cendres dans le sol (environ io à i 5 bronettes de terreau par perche carrée); dans la suite un pen de terrean mêlé aux fenilles puis couvrir le sol en manière de paillis chaque antomne et chaque printemps, an moins 3 pouces d'épaisseur à l'autonne et moins au printenups. 
Le Ginseng demande un terrain qui conserve l'humidité sans être sourceux et froid.

Si le sol est argilenx, une libérale addition de sable et de terreau sera nécessaire pour l'ameublir et l'enrichir.

N'oubliez pas que le choix du sol est pour ainsi dire, le point de départ du succès dans cette culture.

On ne réussira jamais à produire avantageusement le Ginseng dans un terrain primitivement occupé par des essences de bois résineux.

Là où il y a eu du sapin, dı pin, le Ginseng ne croîtra que misérablement.

Encore une fois le meilleur terrain pour cette culture est celui qui a été occupé autrefois par l'érable, le tilleul, le bois blanc, le chêne, le noy'er, le hêtre et autres essences de bois dur, excepté le merisier dont la feuille de cet arbre est fort préjudiciable au développement du Ginseng. Quand il est reconnu qu'une terre peut produire encore de nos jours ces sortes de bois, on peut sans crainte l'adopter comme sol parfaitement convenable à la culture du Ginseng.

Il faut extraire du sol, en le préparant, tous les corps étrangers, pierres, racines, bouts de bois, etc., etc.

On conseille d'appliquer 4 à 5 ponces de terrean sur le terrain ameubli et nettoyé d'une épaisseur de $1 \frac{1}{2}$ à 2 pieds, une conche de cendres de bois franc d'un demi ponce et d'enfonir le tont (cendres et terrean) pen profondément avec la bêclie on la cliarrue.

\section{OMBRAGE}

Le Ginseng ne croît que sons ombrage naturel ou artificiel, pratiqué de manière à ne laisser pénétrer qu'environ un tiers des rayons du soleil. Des panneaux de lattes ordinaires, arec $3 / 4$ de pouce d'espace entre elles, et assez élevés pour circuler en-dessous donnent entière satisfaction. L'on peut suppléer aux lattes par des broussailles déposées en quantités suffisantes sur une cliarpente. I,a culture sous bois dans la forêt sous ombrage suffisant réalise la condition naturelle. Il en est de même sons les arbres fruitiers si le fenillage est assez dense et les arbres assez rapprochés. L'ombrage des bâtiments peut être ntilisé mais se défier de trop de fraîcheur et des eaux d'égoût des convertures. Pour une petite exploitation, certaines plantes grimpantes dont la vitalité et le fenillage sont antérieurenent assurés ronneront aussi satisfaction. 
Pour obtenir l'ombrage au moyen de lattes, il faut planter 2 pieds dans le sol des piquets en cèdre ( $\mathrm{si}$ possible) de 8 pieds de liauteur à 8 pieds de distance entre eux, relier ces pieux à la tête aı moyen de tringles suffisanınent fortes pour recevoir les panneaux de lattes.

Des petites gaulettes de cèdre ou épinettes éviteront l'achat de ces tringles. Ces panneaux ou sections penvent être de $S$ pieds par 4, si l'on a commodément des pièces de $S$ pieds pour clouer les lattes dessus, sinon il sera aussi bien de les construire de 4 pieds carrés. Alors on peut se servir de lattes pour les montants en les donblant pour ces montants si elles sont trop minces.

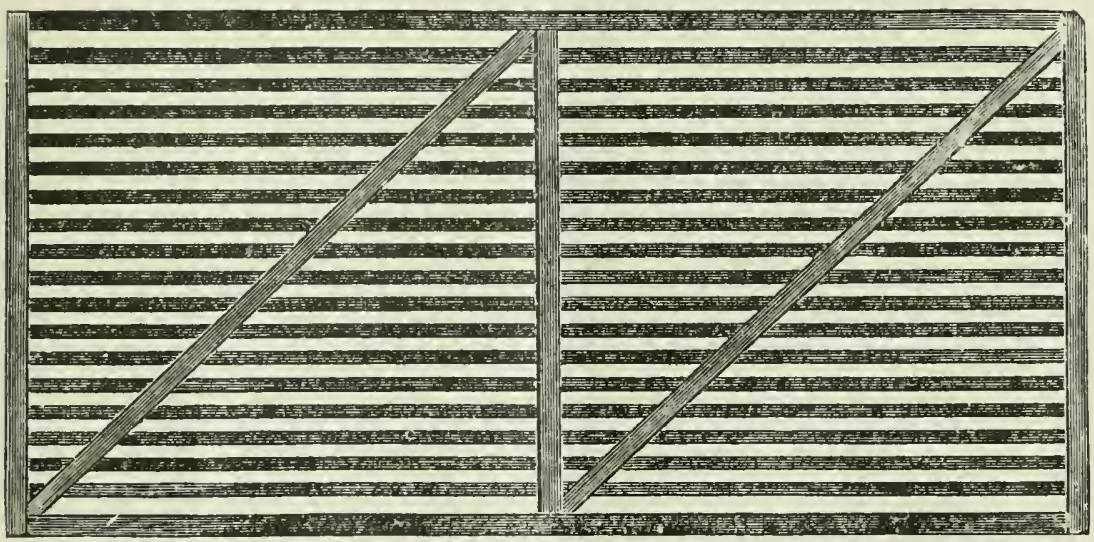

PANNEAU MOBILE DE $4 \times 8$ PIEDS (Fig. 3 )

Dans le cas de panneanx de $4 \times 4$ pieds il faut nécessairenent plus de tringles on gaulettes pour la charpente. Ces panneaux sont renisés en liver car la neige les écraserait. Ils doivent être replacés au printemps (en avril).

le côté exposé au sıd-ouest, c'est-à-dire au soleil devra être protégé aussi par un treillage suffisant.

\section{IITS OU COUCHES}

Quatre pieds de largeur et allées d'un pied. Des bordures en lisières de bois de 5 pouces de largenur et d'ı11 pouce à $u 11$ ponce et deni d'épaisseur devront être placés le long de ces lits formant en même temps les allées. Des petits piquets retiennent cette bordure. Ces allées ont 
aussi une profoudeur de 5 pouces : la terre enlerée pour faire les allées est répandue sur les planches qui doivent avoir la même hauteur que ces bordures. Le défoncement du sol, l'addition des terreaux amènent ce résultat et ceci facilite aussi l'égoût. Pratiquer ces allées aussi els vue de cet égôtt leur donnant une inclinaison légère vers un endroit récepteur et déchargeant.

A l'aide du ratean on doit donner aux lits une surface régulière et en enlever tout ce qui n'est pas nécessaire, bois, pierres, branches, pailles, etc., etc.

\section{PLANTATION DES GRAINES}

Ne jamais les laisser sécher, car à peine y a-t-il 5 graines sur 100 qui lèvercnt. Les vendenrs de graines de Ginseng les conservent à l'état frais par la stratification. C'est pourquoi vous devez vous hâter de les mettre en terre aussitôt que vous les avez reçues, et c'est pour la même raison que vous ne deve\% acheter que des graines stratifiées et éprouvées à l'eau.

La surface de la couche on lit devra être bien anenblie. Semez les graines à un pouce de profondentr et à 2 pouces de distance les unes des autres en tous sens.

Préparez cette couche de terre riche et friable de telle sorte que l'on puisse y plonger la main à 5 on 6 pouces sans difficulté. Après avoir semé ces graines reconvrez la surface de la couche d'une certaine épaisseur de fenilles mortes ou de fumier de clieval bien pourri, de même que la nature les protégerait dans la forêt. Si la plantation se fait au printemps cela aura aussi pour résultat d'empêcher l'herbe de pousser; la paille de sarrazin rend le même service.

Servez-vous toujours d'une planche dont les extrémités s'appuient sur les bordures, soit pour planter soit pour sarcler, afin de ne pas tasser rles pieds ou des mains la surface de la couche.

Pour semer des quantités considérables de graines, cette planche encochée à demande à ses extrémités servira à repousser la terre un pouce d'épaisseur sur une certaine longueur dans le sens de la couche. Il est bou de mêler suffisamment de la fleur avec les graines afiu de les suivre de l'œil et de corriger l'espace entre les graines trop rapprochées ou trop éloignées. Puis l'on ramène la terre refoulée au moyen de la planche ou de la main. Il faut 2 personnes pour se servir de cette planche.

Il est indifférent de semer les graines le printemps ou 
l'automne. Cependant, vu que cette graine prend is mois pour germer, il est préférable de ne pas semer le printemps des graines stratifiées qui doivent lever le même printemps, et il est à propos de semer à l'automme des graines devant lever le printemps suivant. L'on pent semer du printemps à l'autonne, en aucun temps, des graines stratifiées de la précédente récolte, c'est-à dire récoltées l'automne auparavant.

Vu que l'endroit de la couche deviendra un lit permanent, c'est-à-dire où l'on y plantera subséquemment les petites racines, il vaut mieux en préparer le terrain à cette fin, suirant les indications ci-dessus et spécialement la suivante autant que possible eı égard à la superficie à préparer.

\section{PRÉPARATION DU SOL POUR LIT PERMANEN'T}

\section{D'APRËS UN BON CULTIVATEUR DE GINSFNG}

I. Bêcher et déposer à côté de la couche la première piquée de terrain ;

2. Bêcher pareillement (mais sans l'eniever) et ameublir le sous-sol en y incorporant le fumier à notre disposition en quantité libérale, le pluss décomposé possible, mais en réservant le plus pourri à la piquée du dessus ; fumier de cheval seul préféré ; (le fumier de cheval et vache mélangé est considéré comme bon aussi.), mais très pourri. Il fant aussi confier au sous-sol un peu plus que le tiers de terreau; puis ramener la première piquée en la mélangeant arec le fumier le plus décomposé et balance de terreau dont on réserve une partie pour en faire la toilette de surface.

\section{APRES LA PLANTATION DES GRAINES}

Aussitôt la plantation finie, on arrose légèrement le tout puis on couvre arec des feuillages décomposés à raison de $2 \frac{1}{2}$ ponces d'épaisseur, 3 pouces de feuilles sèches et après cela on jette des branchages ici et là pour empêcher le rent d'emporter les feuilles.

\section{CON'TRE LA GELÉE}

Ces soins minutieux, convertures de feuilles décomposées et broussailles ont pour but de protéger la plantation contre les gelées d'automne et d'hiver; imitons la nature 
en tout et partout. Dans les bois, la graine de Ginseng se détache de sa hampe vers la mi-août et tombe sur les feuilles décomposées de l'année précédente ; ensuite la tombée des feuilles de l'automne la recouvre et à la fois la protège contre les gelées et les dégels de l'hiver.

\section{PLANTATION DES GRAINES À DEMEURE} PERPÉTUELLE

Je connais des cultivateurs de Ginseng qui conseillent de ne pas planter les graines en couches, mais de les planter de suite à la distance đes plants, c'est-à-dire de 5 à $\mathrm{S}$ pouces daus les rangs et même distance entre les rangs. Quand le terrain ne manque pas, on conseille même ume distance de 9 pouces en tous sens, et cela, dans le but de protéger les plants contre les vers.

\section{PLANTATION DES RACINES OU PLANTS}

La meilleure saison pour cette opération est l'autonne du 15 septembre au is octobre, alors que la racine a formé son bourgeon pour sa tige de l'année suivante, car planter avant cette formation serait s'exposer à des déboires. La plante peut être transplantée l'automne de la même année qu'elle a levé, ou le second automne après telle levée. La distance peut être de 5 à $S$ pouces dans le rang en tous sens, mais encore une fois il est préférable d'adopter une distance de 9 pouces en tous sens. L,e plus d'espace donnera plus de rendenent si l'on ne tient pas compte des frais d'installation. Le bourgeon de chaque plant devra être recouvert de 2 pouces de terre et la plante enfouie avec une inclinaison de 45 degrés en ayant soin d'étendre les radicelles, filaments et surtout de ne pas briser le bourgeon.

Une planche de 9 pouces de largeur et $1 / 2$ pouce d'épaisseur s'appuyant sur les bordures, placée en travers du lit sur laquelle le planteur peut s'agenouiller rendra l'opération facile, si sur un côté de cette planche on en cloue une autre plus mince devant s'enfoncer deux pouces dans le terran. Cette dernière indiquera la profondeur à partir de laquelle se trouvera le bourgeon au sommet du plant. On creuse le sillon avec la truelle à jardinier toujours en avant de cette planchette sur laquelle des marques placées indiquent à chaque rang l'espace entre chaque plant. 
Voici un autre procédé pour faire nue démarcation en tous sens, me disait $u 1$ cultivateur de Ginseng qui ajouta les remarques suivantes :

Pour faire une démarcation de 9 pouces en tous sens, je me sers d'une planche de $1 / 2$ pouce d'épaisseur, 9 pouces de largeur et de 12 à I 5 pieds de longueur. J'en ai une autre de même largeur mais semlement de 4 pieds de longueur dont je me sers pour marquer dans le sens de la largeur du carré.

Il vaut mieux attendre au 2ème automne pour transplànter les petites racines parce qu'il y a parfois des

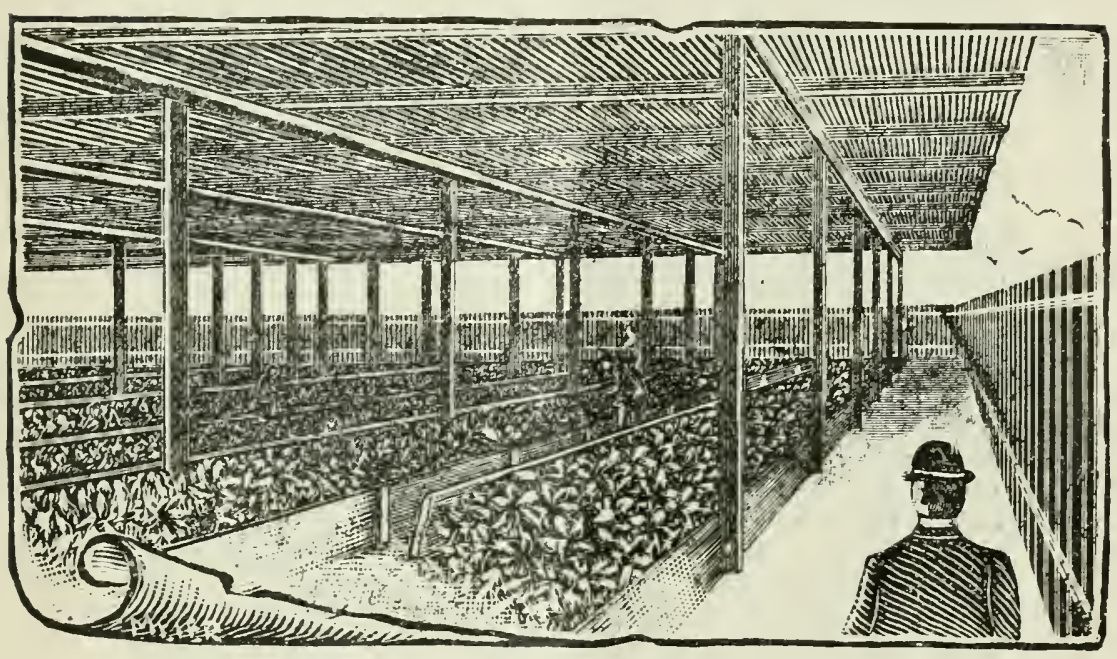

JARDIN DE GINSENG (Fig. 4)

graines paresseuses, surtout celles qui ont mûri tard, qui retardent au leuxième printemps pour lever. En transplantant le ser automne on se trouve à bouleverser la couche et à détruire celle ainsi en retard.

Le travail du repiquage ou transplantation doit se faire avec le plus grand soin. Je fais les trous avec mon plantoir puis je saisis la racine par l'extrémité du collet et je l'introduis dans sa fosse respective à une profondeur suffisante pour qu'il y ait deux bons pouces de terre pardessus le collet. On trouve souvent dans les bois, des racines jusqu'à Io pouces de profondeur et généralement 
ce sont les plus grosses. Plus une racine de Ginseng est âgée plus on la trouve enfoncée dans le sol, en vieillissant elle ne cherche qu'à descendre. En faisant le repit quage il faut avoir soin que la terre adhère fortement tout autour de la racine, ne pas faire non plus les trous trop profonds afin d'éviter que la pointe de la racine reste dans le vide. Une fois le repiquage exécuté, je couvre ma plantation avec des feuilles décomposées de l'année précédente (environ $21 / 2$ pouces d'épaisseur) et je rajoute immédiatement 3 pouces de feuilles de l'année ; j'arrose le tout copieusement et je mets sur ces feumllages des branches pour empêcher le vent de les emporter.

\section{CROISSANCE DU GINSENG}

La graine doit rester en pépinière pour être ensuite transplantée en pleine terre à l'automne entre le 15 de septembre et le 15 octobre.

Le Ginseng commence à sortir de terre lorsque les bourgeons des arbres commencent à s'épanouir et les graines lèrent une dizaine de jours après les racines. Aussitôt après les sucres, en enlève les branches de sur les carrés, il est bon d'enlever quelque peu des feuilles sèches afin que la terre se réchauffe le plus tôt possible. Quand les racines sortent de terre il faut mettre inmédiatement les panneaux d'ombrage artificiel qu'on enlèvera à l'automnc. Le Ginseng lève en forme de crochet, la tête en bas. An bout de 5 à 6 jours la plante est com. plètement redressée et on en distingue tous les organes : 3 branches, 5 feuilles par branche et sa hampe florale an centre. Lorsque la graine lève, il ne faut pas lui toncher car le germe est extrêmement délicat, le moindre palper pouvant le faire mourir. C'est pourquoi le besoin d'un abri artificiel se fait sentir pour protéger les graines, les plants contre la vivacité et le manque de respect de la part des

Volailles, chats, chiens, oiseaux et voleurs.

A partir de la levée de la graine il faut laisser le carré tranquille.

Une jeune plante du printemps a vers l'automne une hauteur de 3 à 4 pouces et une racine de même longueur. La seconde année la plante possède 2 ou trois tiges feuillues chacune portant de 3 à 5 feuilles et atteint tme hauteur de 5 à 6 pouces.

La troisième année chaque tige a 5 fenilles, en tout ${ }_{5}$ feuilles et sa hauteur est de $S$ à 10 pouces. 
Après trois ans, la plante se garnit de i 8 à 25 feuilles et a une hautenr de is à 25 pouces.

Un certain nombre de racines de 4 ans peuvent être livrées an commerce dit le Journal d'Agriculture, page 25.3, I904, mais moi je conseille d'attendre à la 6ènıe année de végétation, ce qui fait 7 ans à partir de la plantation de la graine stratifiée.

\section{QUELQUES SOINS DE CULTURE}

I. Si la sècheresse de juin et juillet persistait, il faudrait nécessairement faire $t n$ bon arrosage par semaine, particulièrement sur les semis.

2. Si les sarclages de la culture du Ginseng, soit artificielle soit sous bois, se réduisent à peu de travail, il faudra néanmoins, enlever les mauvaises herbes à mesure qu'elles se présenteront, car le sol devra toujours être net, propre, durant au moins les 2 ou 3 premières années.

3. Encore une fois ne pas oublier à l'automne, après le 15 octobre, de mettre une conclie de 3 pouces de feuilles mortes décomposées de l'année précédente au moins, une très légère couche de cendres de bois franc, puis une couche de femilles mortes de l'année, puis enfin, des branches pour maintenir les feuilles en place.

4. Ne jamais tenir les allées trop nettes d'herbes, car les insectes entrant dans l'exploitation, mouches quelconques ne se repaitront que de feuilles de Ginseng si aucune autre végétation ne s'y trouve.

5. Si l'eau qui monte sur les terres le printemps, n'y séjourne pas longtemps, cela ne peut être dommageable en rien à cette culture puisqu'alors il n'y a pas de chaleur dans le sol.

\section{UN FAIT SINGULIER - PRODUCTION DES GRAINES}

Voici ce que me disait l'un de mes deux amis qui m'ont fourni de si précieux renseignements sur la culture du Ginseng :

"J'ai constaté une anomalie qui de prime abord m'a paru bien étrange. Il y' a deux ans, $\mathrm{j}$ 'ai eu une quinzaine de pieds qui m'ont produit 8o, 90, roo et même Io5 graines; l'année suivante, ces pieds si prospères d'abord, sont restés rabougris et plusieurs d'entre eux n'ont même pas levé : j'ai examiné ces plantes avec soin pour m'assu- 
rer si les bestioles ou la gelée ne les auraicnt pas endommagćes. Mais non, les racines étaient en parfaite santé ; alors je pris des informations an sujet de cette racine capriciense. On m'a répondu que les plantes qui produisent beaucoup de graines se cachent et se reposent l'année suivante. et que dans leur retraite souterraine, elles profitent d'autant plus qu'elles n'ont pas de sève à distribuer à la cluarpente externe. On m'assure que durant cette année de repos, ces racines acquièrent double poids, c'est-à-dire qu'elles profitent deux fois plus que celles qui suivent le cours régulier de la végétation. Je compte aroir 15 pour 100 de ces racines à pousse irrégulière.

\section{CUEILLETTE DES GRAINES}

La graine commence à mûrir vers le 10 août. On les cueille lorsque les baies sont parfaitensent ronge-écarlate et au fur et à mesure qu'elles mûrissent. Ne janiais les toucher inutilement ou heurter de façon quelconque car elles pourraient s'égrener. Il y a toujours bénéfice d'inspecter le terrain en dessous des tiges pour ramasser les graines tombées que l'on met en sûreté et qu'on stratifie en même temps que celles que l'on récolte.

\section{STRATIFICATION DES GRAINES}

Il y a deux procédés un peu différents qui ont égaleunent réussi à mes deux amis, ce qui proure qu'il est bien

- vrai ce proberbe qui dit que Tout chemin mène ì Rome. Pour la satisfaction des lecteurs je rais citer ces deux procédés, vu l'importance de cette phase du sujet :

\section{PREMIER PROCÉDÉ, DE STRA'TIFICATION}

Je laisse la parole à mon ani :

"Après la cueillette, je dépose mes graines dans une boîte à brandy (vide naturellement) remplie de sable sec à moitié, passé an tamis, et je mélange nues graines avec le sable. Alors la graine se bonifie et parvient à maturité complète. Les baies sont cliarnues et contiennent beatscoup de jus.

Après trois semaines de séjour dans le sable, je les trouve entièrennent décomposées. L,orsque je constate que la graine s'est rébarrassée de son enveloppe, je passe le tout au tamis pour extraire complètement la graine de son enveloppe. Je me sers, à cet effet, d'un tamis un pen 
plus gros que celui à graine de mil ; on peut aussi la sasser sur un morceau de toile (moustiquaire). Après cette opération, je lave mes graines comme il fant, je les verse dans mn essuie-mains pour les laisser égontter pendant une couple d'heures, après quoi je les empote.

Le terreau des bois dont je me sers pour faire germer mes graines est de première qualité et je le passe au tamis avant d'y mélanger mes graines.

Dans un bocal de cristal contenant environ un pot, on peut y mettre germer 3000 graines; je mélange ma graine dans le terrean avant de l'empoter pour obtenir un meilleur mélange; c'est ce que les Ginsengmen appellent mettre les graines en stratification. Je bouche mes pots et je les dépose daus la cave mais toujours dans un local à l'épreure de la gelée.

Par exemple les graines que j'ai récoltées l'automne dernier ont passé tout l'hiver dans la cave, au printemps j'ai sorti mes pots que j'ai mis dehors, dans un trou et que j'ai recouverts de terre; cet automne je les sortirai de terre pour semer mes graines qui seront, j'en suis surr, aussi belles que celles que je prépare ainsi depuis 3 ans. Ces graines devront être semées cet automne, autrement elles seraient perdues car elles germeraient dans les pots. Cette graine lèrera le printemps prochain, ce qui fera i 8 mois d'écoulés depuis la cueillette, c'est-à-dire I 2 mois de stratification et six mois en terre avant de lever."

\section{DELXIËMH PROCF́DÉ DE STRATIFICATION}

D'après le denxième ami que j'ai rencontré :

"A la veille de la maturité des graines se pourvoir l'une certaine quantité de sable que l'on fait d'abord sécher pour le sasser dans nu sas aussi fin que pour la farine, puis humecter ce sable sans le noyer. Lorsqu'une première quantité de graines est récoltée, se procurer une boîte de grandenr convenable (uve boîte à poivre pour un débutant) pas trop étanche, déposer au fond une conche de sable humide d'un pouce d'épaisseur, puis étendre nne couche de graines avec leur pulpe aussitôt en les cueillant, d'une senle épaisseur (un lit) pen importe qu'elles se touchent. Courrir ce rang de graines d'une autre couche de sable et continuer de cette manière jusqu'à ce que lá boîte soit remplie, la clemière couclie devant être de sable mais plus épaisse que les précédentes.

Après 2 on 3 semaines, repasser ce sable et ces graines 
dans le même sas, en l'y déposant par jointée et y versant de l'eau au-dessus d'une curette ; le sable s'amasse dans cette dernière et les graines débarrassées de leur pulpe en décomposition, sont tout-à-fait propres et prêtes à être déposées dans la même boîte avec d'autre sable aussi sassé et humecté (à raison de 3 fois autant de sable que de graines). Cette hoîte peut alors être déposée dans une cave fraîche, mais enveloppée dans du sas à broche, à chassis ou autre treillis pour la protéger contre les rongeurs, ou mieux, enterrée dehors dans un endroit frais et non humide. Si ce dernier mode est choisi, clouer sur le dessus de la boîte un morceau de toile métallique supportée par quelques lattes, puis enfouir cette boite (sans dessus dessous) presqu'à efflemrement de la surface du sol. La gelée ne fait rien.

\section{CULTURE DU GINSENG SOUS BOIS}

Je vous avouerai bien franchement que $j$ ai peu de confiance à la culture du Ginseng dans la forêt, pour s'épargner l'ombrage artificiel. D'abord les produits sont exposés à la cupidité des voleurs, et à la voracité des oiseaux qui mangent les graines; et, ensuite les travaux d'entretien sont énormes.

A part cela, la racine croît avec une lenteur découragreante. Une racine qui a vécu 8 ans sous l'ombrage artificiel aura double pensanteur à celle des bois de 25 à 30 ans d'âge. Une racine des bois grosse comme le pouce est âgée de 27 à 35 ans On a constaté que des racines des bois de to et $I_{5}$ ans n'étaient pas plus grosses que le petit doigt.

Il ne faut pas s'étonner de la croissance tardive et lente de cette racine dans la forêt à cause dn sol qui est très compact, rempli de radicelles et tissé de racines de toutes espèces qui gênent considérablement la plante. Toutes ces tiges, courants, etc., sont autant de tubes qui absorbent l'humidité du sol si utile à sa prospérité, tandis que dans la culture artificielle, la plante ne rencontre pas ces inconvénients. Quel travail que celui de défoncer le terrain des bois, surtont si les arbres de l'endroit sont gros, tout en ayant soin de choisir les plus belles clairières.

On rencontre des racines de toutes grosseurs ; sourent le sol est rempli de pierres à enlever, d'excavations qu'il faut remplir. Je n'exagère pas les obstacles, me clisait un cultirateur qui a fait cet essai : j'ai préparé moi-même des carrés daus le bois, et je suis at courant des nom- 
breuses difficultés que présente la culture dans ce lieu. Quand un homme a bêché un carré de Io pieds par 4 dans sa journée, on se montrerait cruel de lui en demander davantage. La préparation des plates-bandes dans les bois est un travail exubérant, par conséquent fort dispendieux. Voici ce qu'ajoutait mon ami qui a fait cette culture : "Lorsque j'ai bêché mes carrés dans le bois, j'ai eu soin d'enlever toutes les petites racines que j'ai rencontrées. Deux ans après, en arrachant mes jeunes plants, j'ai trouvé mes carrés tissés et remplis de racines, de chevelus, de poils de tous genres, j'ai ramassé

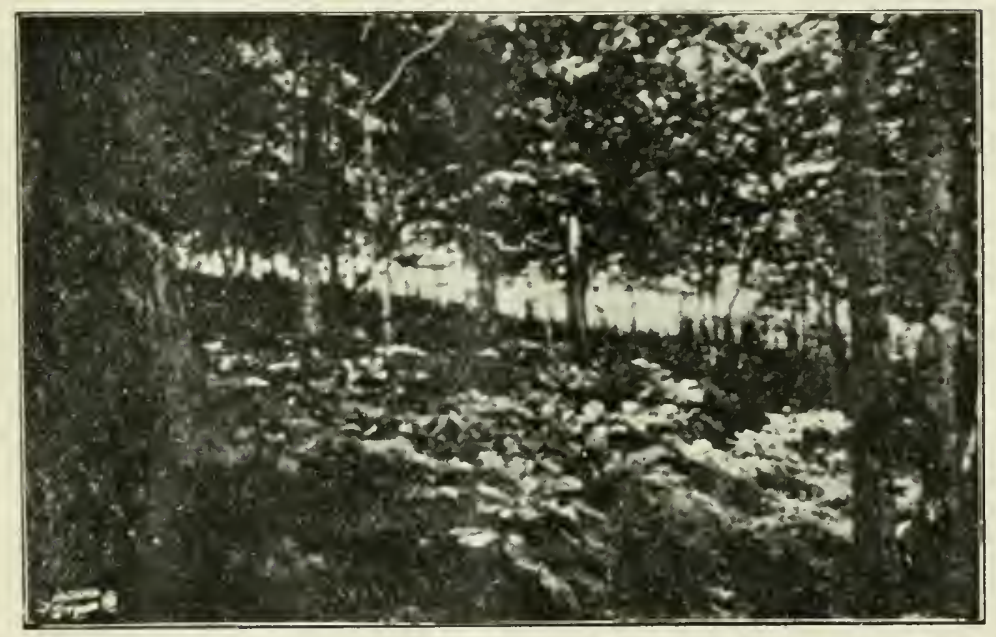

CULTURE DU GINSENG SOUS BOIS (Fig. 5)

et secoué tout cela sur un carré de Io par 4 pieds. Il y avait une pleine brouette de cette filasse. Je ne crains pas d'affirmer, après une expérience aussi démonstrative que le défonçage dans le bois favorise énormément la reprise des cheveux souterrains.

Un débutant a besoin de graines pour augmenter sa culture tous les ans sans compter qu'il peut faire de l'argent en vendant ses graines à ses voisins. Or, il est constaté que les racines, sous l'ombrage artificiel donnent 3 fois plus de graines que celles des bois, et c'est facile à comprendre attendu que la plante sous les lattes voit le 
soleil depuis son lever jusqu'à son coucher, ce foyer fécondateur de toutes cheses, tandis que sous bois, la plante roit moins de soleil et à part cela, sous les lattes, les grai11es ne sont pas exposées à être mangées par les oiseaux, spécialement la grive et la perdrix qui en sont friandes au point qu'elles les mangent avant leur maturité.

Voici ce que dit le Joumal d" Agrinulture page 253, I 904 : "Quoique l'on puisse cultiver le Ginseng en forêt dans un sol enrichi où on a défriché le sous-bois, les vrais cultivateurs de Ginseng préfèrent établir un abri artificiel consistant en un treillis ou latté en bois posé horizontalement à 6 ou 7 pieds au-dessus du sol, sur une charpente construite à cette fin

En voici assez, je crois, pour vous démontrer que la culture sous ombrage artificiel est préférable à la culture sous l'ombrage de la forêt.

\section{L'AGE DU GINSENG}

On reconnait facilement l'âge dı Ginseng en comptant les marques des années sur le collet.

Le bourgeon qui produit la tige ne se développe janais au même endroit. A tous les automnes, il change de logis ; il prend naissance sur la bosse du collet et suit sa marche circulaire. A chaque automne, le bourgeon laisse la trace bien visible de son passage : et nous n'arons qu'à compter les petits trous que nous remarquons tout autour du collet et nous arons exactenent l'âge du Ginseng.

Un cultivateur m'a déclaré qu'il avait trouvé de belles grosses racines de Ginseng en plein chanp au milieu de grands framboisiers ce qui prouve que la plante est rustique et a besoin de soleil, car sous bois jamais ces racines auraient atteint ce volume. Elles étaient âgés de 25 ans, et quadruplaient le rolume de racines de cet âge tronvées dans les bois.

\section{RECOL'TE DU GINSENG-L'ARRACHAGE}

Cette opération de l'arrachage demande beaucoup de soins.

Les racines cultivées sont incomparablement plus faciles à extraire du sol que celles restées à l'état sauvagre.

Après l'arrachage on procède au décolletagre et au ratissage des produits; avec un canif bien aiguisé, on coupe le collet à l'effleurement des épaules et on ampute la couron11e de la racine ayant bien soin de ne pas endonnma- 
ger les bourgeons ; ces collets sont repiqués immédiatement en pleine terre de 9 pouces en tous sens. A leur tour ces collets donnent des racines aussi belles que celles provenant du jeune plant ou de la graine. La reprise du
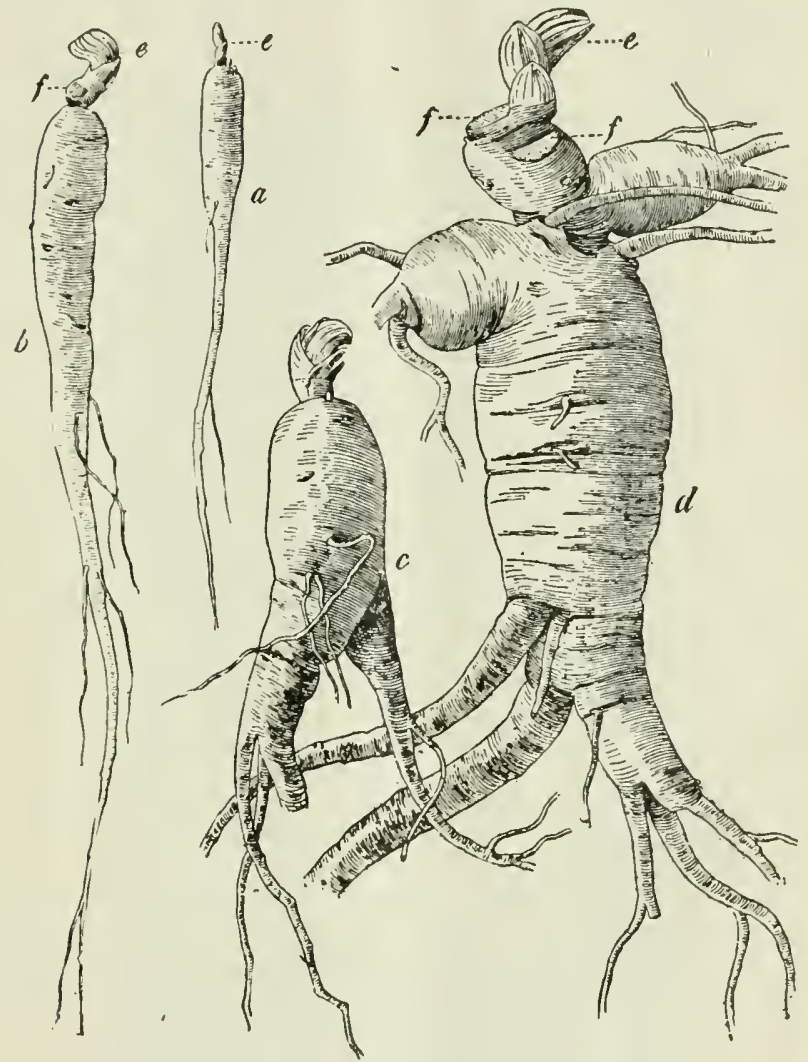

(Fig. 6)

Racines de Ginseng à l'etat frais provenant de plants cultivés

a. âgée d'un an ; b. âgee de 2 aus ; c. âgée de 3 ans ; d. âgée de 4 ans e. bourgeon.

collet ne s'effectue pas aussi régulièrement que le jeune plant. La première année, il en lèvera 40 à 50 pour 100 . $\mathrm{A}$ la deuxième année il lèvera 75 à 80 pour Ioo. On peut dire qu'en général 75 pour roo des collets que l'on transplante seront bons. 
Quant aux collets dont les bourgeons auront été brisés. ils devront être mis de côté car ils sont impropres à la reprise.

Le ratissage des racines consiste à enlever les petites racines et les chevelus et à rogner la pointe de la racine proprement dite. Ces fragments de racines sont mis à part. Les racines doirent être lavées à l'eau naturelle, jamais à l'eau chaude. Plusieurs se servent de brosses de chien-dent ou celles de broches fines, ce qui n'est pas recommandable car on égratigue l'écorce de la racine. On doit se contenter d'un morceau d'étoffe ordinaire et ne pas frotter trop fort afin de ne pas enlever les rugosités qui sont très délicates sur la racine cultivée et qu'on remarque sur les racines saurages et que les consommateurs, paraît-il, tiennent à avoir.

\section{LE SÉCHAGE}

Après avoir lavé les racines comme je viens de le dire. on les laisse égontter durant quelques heures.

On ne doit jamais, jamais, faire sécher les racines dans le four conme cela se pratique généralement, ni sur des. tôles dans les fonrneaux du poële.

Une dessiccation trop rapide et à la chalenr trop intense affecte considérablement la qualité cles produits et sa couleur ; dans ces conditions, il perd sa belle couleur blanche 'qu'il doit avoir et gon̂te le brîlé.

Bien des acheteurs se plaignent de ce mauvais procédé, disant qu'ils veulent acheter du Ginseng naturel, mais. non dénaturé.

Le séchage doit se faire dans nul local assez chaud et ̀̀ une température régulière, où il n'y a aucune odeur étrangère et repoussante. De même que le lait qui séjourne dans l'écurie prend le goût d'étable et le communique au beurre, les racines s'empareront des odeurs désagréables qui les entoureront et perdront de leur valeur.

Dans i'appartement où l'on fait sécher les racines, il vaut mieux exclure toute odeur, même l'odeur de renfermé qu'on fera disparaître par la ventillation répétée de temps à autre. Je ne crois pas que le parfum des fleurs nuise à la qualité des racines. Certains cultivateurs les font sécher sur des draps blancs suspendus an plafond de la cuisine, ce que je n'approuve pas à canse des odeurs qui s'émanent du poële de cuisine; d'autres les mettent sur cles planches ou autre bois résineux, ce qu'il faut éviter vu que le produit prentrait le goût rles essences de ces bois. 
Si on a une quantité assez forte de racines à faire sécher on pourrait se procurer des évaporateurs à fruits. En attendant contentez-rous de draps suspendus et déposés dans une chambre exempte d’odeurs désagréables. On compte qu'il faut 3 mois pour obtenir une dessiccation

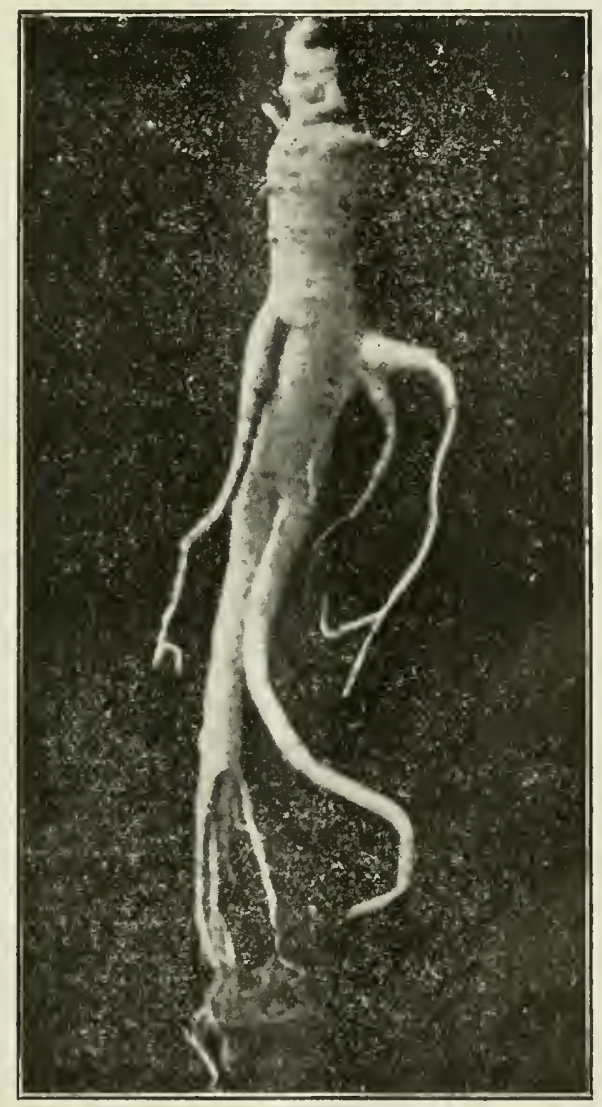

(Fig. 7)

Racine de 5 ans, bonne pour le marché. Très reduite en volume.

parfaite. Les acheteurs se montrent très difficiles et scrupuleux, lorsque les racines contiennent de l'humidité. Quand une racine fait du bruit en la cassant c'est qu'elle est parfaitement sèche. 


\section{TRILLAGF, DES RACINES E'T EMPAQUETAGE}

On y gagnera beancoup en faisant $n$ bon trillage et un bon empaquetage.

Lorsque les racines sont parfaitement sèches il faut les classer par ordre de grosseur, forme, couleur, etc., surtout celles qui approchent le plus la forme humaine. Il fant éviter avec soin l'humidité, car la transpiration des racines nuit énormément à leur valeur. Il ne faut pas aussi exposer ce produit au contact des insectes, mites, fourmies. etc.

Un bon moyen est de les placer dans des jarres fermées hermétiquement en attendant la vente.

Quand le temps d'expédier la marchandise est arrivé, l'on y gagnera beaucoup à ne pas former des lots considérables. On mettra les racines telles que classées dans des sacs de papier fort, beau, sec et propre, attachés avec soin ou dans des boîtes de même grandeur, très propres ne contenant pas plus qu'une livre, tapissée en dedans d'un beau papier blanc. On déposera ces sacs on petites boîtes dans une grande boîte également bien propre et tapissée à l'intérieur d'un bean papier blanc.

Faites en sorte que l'extérieur des boîtes soit très propre aussi.

\section{ENNEMIS DU GINSENG}

Cette plante connait pen d'ennemis, dı 1110ins pour la présent.

On peut redonter les vers il est vrai ; mais en plantant les graines à 9 pouces de distance en tous sens an lien de 2 pouces et les jeunes plants à 9 pouces en tous sens, on conrt bien plus de cliances de restreindre de beanconp les: ravages. Il y a une mialadie spéciale qu'on a renarquéc dans un champ de Ginseng (aux Etats-Unis) et c'est le senl sur des milliers, c'est l'échaudage on blight dont on vient aisément à bout par l'application de la Bonillie hordelaise : Chanx vive, + livres; Vitriol blen en poudre, 4 lirres; Vert de Paris. 4 onces ; Ean 40 gallons. On conseille même comme traitement prérentif d'arroser les lits de bonne henre le printemps avec cette préparation an moyen d'une pompe pulvérisatrice.

\section{PE'TITES REMARQUES}

I. Une lirre de graines de Ginseng contient 8,000. graines. Les deux tiers contiennent 2 graines chacune: 
quelques-unes en contiennent 3 ; le petit nombre en contient une. Mais les graines de semence se vendent rarement à la livre ; généralement elles se vendent au roo.

2. Un carré de $32 \times 32$ pieds bien cultivé peut rapporter en 7 ans $\$ 775$ en supposant que les racines ne pèseraient que 2 onces, tandis qu'en réalité le poids de chaque racine sera plutôt de 4 onces.

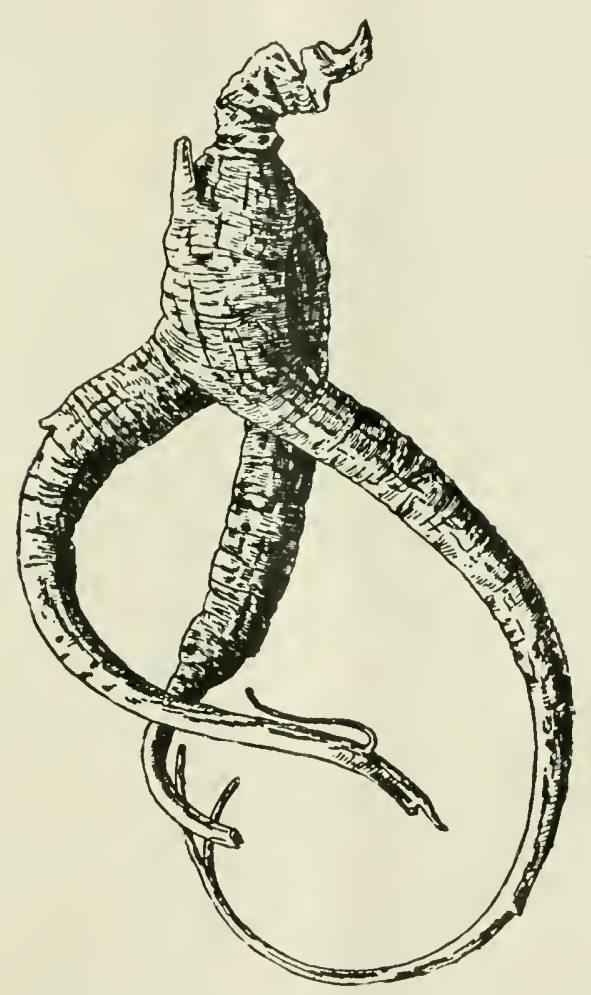

(Fig. 8)

Racine de Ginseng desséchée

\section{LA CULTURE DU GINSENG DANS I,E, MANITOBA E'T LE NORD-OUEST}

Il ne m'en coûte pas de garantir le succès de cette culture dans les Provinces de Québec, Ontario et les Provin- 
ces Maritimes, mais il n'en est pas ainsi du Manitoba et du Nord-Ouest. Tout de même, je suis porté à croire qu'en faisant des brise-rents, clôtures en planche de ro pieds de hauteur autour des plantations, en faisant de l'ombrage artificiel et en mettant à l'automne, de bons paillis sur les couches et les lits, cette culture réussira car la plante est très rustique. Un des plus grands avantages pour cette culture dans le Nord-Ouest, c'est qu'il y a beaucoup d'humus. Si je résidais dans cet endroit, je n'hésiterais pas à faire l'essai d'une plantation de ıoo graines, avec la quasi-certitude de réussir, soit arec des graines on des jeunes plants.

\section{ENGRAIS SPÉCIAL}

Cette culture n'exige pas généralement d'autres engrais que ceux déjà mentionnés. Mais, cependant, il serait peut-être profitable de suivre le conseil donné un jour par la Ferme Expérimentale d'Ottawa à un cultivateur de Ginseng de l'Ouest d'Ontario à qui l'on a suggéré de faire usage de l'engrais suivant :

$$
\begin{aligned}
& \text { Os monlus fin } 4 \text { parties ; } \\
& \text { Sulfate de potasse } 1 \text { partie ; }
\end{aligned}
$$

On en met 4 livres par verge carrée en ayant bien soin de bien le né́langer à la terre.

Si les feuilles ont une tenclance à jaunir on sèmera sur la terre et la plante $1 / 3$ de livre de nitrate de sonde par verge carrée.

Le cultivateur d'Outario qui reçut ces conseils et les mit en pratique fit rapport à la fin de la saison que les résultats avaient été étonnants.

\section{COMMENT OBTENIR DES RACINES A FORME HUMAINE}

\section{UN GRAND SECRE'T DIYULGLÉ:}

Si vons avez, un grand secret à confier et si ce secret concerne l'iutérêt public, je vous conseille bien de ne pas me le communiquer, car il m'est impossible de le garder. Dernièrement, j'ai vu des cultivateurs que je croyais très intelligents et qui réussissent merveilleusement bien dans l'exploitation de leurs fermes, dans la production du sucre, dn tabac, des volailles, des fruits, etc., et qui sont mécontents contre les gouvernements d'Ottawa et de Québec parce que, par les conférences agricoles qu'ils font donner 
et les brochures qu'ils distribuent gratuitement et à profusion, ils instruisent trop le peuple, et cela leur fait redouter la compétition. Peut-on être plus égoïste ? plus idiot? plus étroit d'esprit ? Aussi verra-t-on ces éteignoirs décourager les cultivateurs en leur conseillant de ne pas aller aux conférences agricoles et de jeter au feu les bulletins si instructifs des gouvernements. Et malheureusement on verra beaucoup de naifs tomber dans le piège.

Mais n'a-t-on pas intérêt de produire beaucoup et bien. N'est-il pas, par exemple, dans l'intérêt de notre pays de

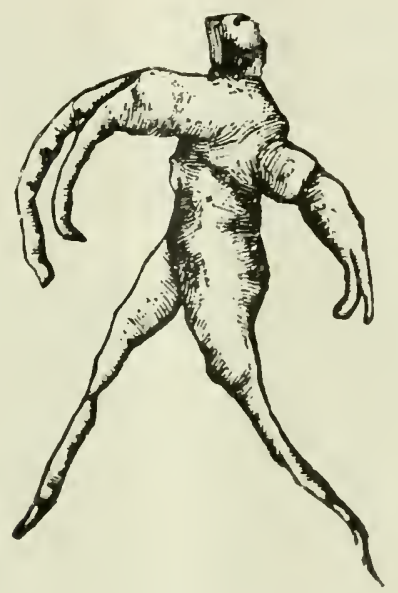

(Fig. 9)

Racine de Ginseng à forme humaine

produire dans d'excellentes conditions beaucoup de beurre, beaucoup de sucre d'érable, beaucoup d'œufs et de volailles, d'augmenter le rendement de nos vaches par une meilleure sélection et une meilleure alimentation, d'augmenter le rendement de nos terres par un emploi judicieux des engrais chimiques?

Produire beaucoup et bien, telle devrait être, il me semble, la devise de tout cultivateur intelligent, et chaque cultivateur derrait communiquer avec empressement à son voisin les secrets de ses succès afin d'augmenter la qualité et la quantité de nos produits d'un bout à l'autre de notre pays. 
Que de remerciements ne dois-je pas à mes deux amis qui m'ont confié sans hésitations les secrets de leurs succès dans la culture du Ginseng avec l'autorisation d'en disposer comme bon me semblera dans l'intérêt du public. Ils ne sont pas des éteignoirs, ces deux amis.

Je vous communique maintenant le secret de donner la forme humaine anx racines de Ginseng et je laisse la parole à mon ami :

"Il y a I 8 mois, j'ai reçu d'un expert cultivateur de Ginseng le secret de produire des racines à forme humaine dont cette forme capricieuse a une si grande valeur aux yeux de lacheteur chinois; si ce dernier trouve dans sa livre de Ginseng une racine qui a cette forme bien remarquable, il tressaille de bonheur ; s'il est riche, il se fera le plaisir de la consommer. S'il est pauvre, il la revendra fort cher aux personnes fortunées; il la vendra d'autant plus cher que la racine se rapprochera le plus de la forme liumaine.

Il serait donc avantagenx de produire un bon nombre de ces racines si bizarres.

L'individu qui m'a donné le secret, m'a ảonné la liberté de le communiquer, mais une senle fois dans ma vie et à une senle persomne. Après avoir réfléchi, je me suis demandé, si je ne ferais pas une bonne œuvre de vous faire part de ce précieux secret avant de mourir. Il me semble que ce secret vous appartient d'autant plus que les diverses opérations qu'il faut faire subir à la racine demandent certaines connaissances chirnrgicales.

L'antomne prochain (1907) j'aurai 6,000 jeunes plants bons à transplanter ; or en arrachant ces petites racines, je suis certain d'en trouver 75 , So et pett-être 100 , qui antront à une distance dı collet deux petites ramifications qui forment les bras et deux autres qui constitueront les jambes: ces racines sont mises à part pour les opérer chacune à leur tour.

Je suppose que vous avez une de ces racines qui a deux ramifications à une petite distance du collet qui forme exactenent les bras, si les bras sont fort disproportionnés disons l'un plus long on plus gros que l'antre, on rognera celui qui est trop long te quant au bras trop gros comparativement à l'autre, on en enlèvera tout le cherelu ; ce bras ainsi ratissé, une fois en terre, prendra moins de nourriture et conséquemment sa croissance sera beaucoup plus lente. Si le bras gauche est plus long que son frère, rognez-le de longeur égale au bras droit ; s’il est grêle, 
laissez-lui porter tous ses chevelus et ses poils et faites disparaître les petites racines proprement dites, car cellesci se nourriront aux dépens du bras, ce qui retarderait notablement sa croissance. Avec toutes ces bouches sur le bras, celui-ci prendra plus d'aliments, et par conséquent, la croissance de ce bras sera plus active que celle du côté droit.

Si un bras est trop court, il faut prendre bien garde de ne pas endommager la pointe de la racine qui forme le bras, car ce bras court n'étant pas rogné poussera à la longueur de l'autre.

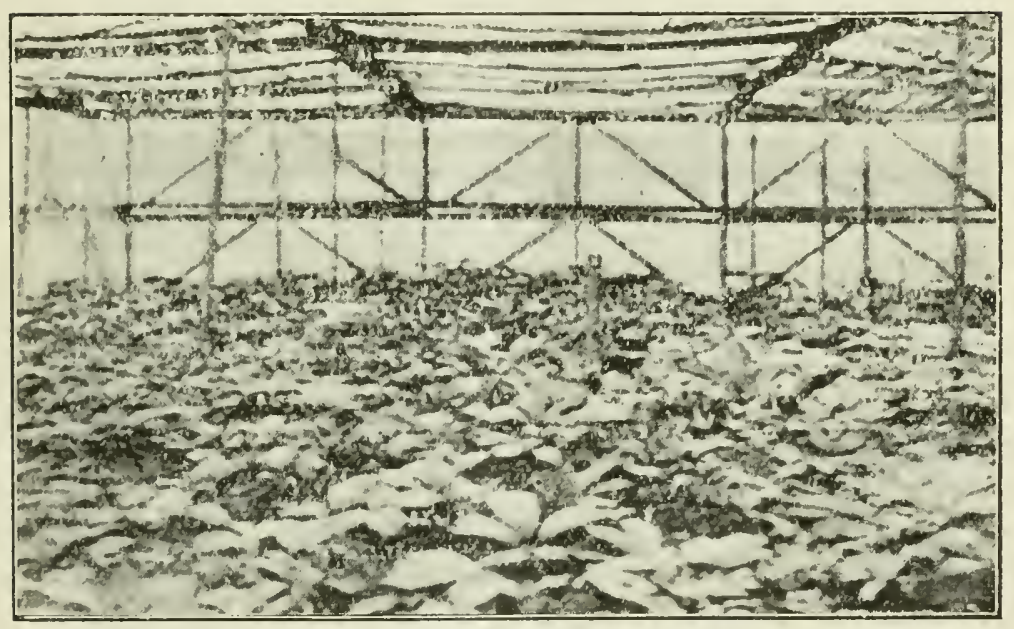

(Fig. 10)

\section{JARDIN DE GINSENG}

Maintenant je suppose que votre sujet a les bras tendus horizontalement, descendez-les en ayant soin de leur faire prendre une forme arrondie auprès de l'épaule, et attacliez-les à cet effet, avec un ruban étroit et mince, de droite à gauche ; dans le cas que votre racine n'aurait qu'un bras tendı, il faudrait le descendre et relever l'autre afin de lui domner une plus belle apparence.

Les diverses opérations que vous venez de faire subir aux bras sont absolument les même que vous aurez à pratiquer anx jambes. Ces racines de clioix doivent être 
plantées à part, avant de les mettre en terre, il faut faire disparaitre toutes les petites racines qui pourraient figurer soit dans le dos ou sur les côtés, sur le ventre ou ailleurs.

Maintenant, il reste une dernière opération et qui est la moins difficile à pratiquer et vous réussirez facilement, car vous êtes chirurgien de profession. L'opération dont il s'agit, c'est de percer la racine de stature humaine par flerrière, en un mot à la grosse extrémité, à l'endroit où le dos perd son nom. Il me semble vous voir rire en lisant cela, mais je vous ai promis un secret, et je vous le donne en entier, sans restriction, en homme consciencieux.

Cette onverture doit se faire 2 ans avant d'arracher la racine pour la vente. Vous déterrez la racine du côté de derrière, puis avec un canif à lame étroite, en choisissant le bon endroit, vous lui faites un orifice d'un demi-pouce de profondeur ; ensuite, vous évasez votre affaire, puis vous lui mettez une cheville et vous replacez immédiatement la terre tout autour de la plante. Un an après cette opération, vous la déterrez de nouveau, vous en enlevez le bouchon et la plaie est guérie, mais il reste le trou chinois.

" Une racine à taille humaine ainsi percée, dit le Country Gentlemen, vaut 15 taëls de plus que celles non percées. Quand une pareille racine tombe entre les mains d'un acheteur chinois, soit riche ou pauvre, il la conserve comme une relique, qu'il traîne dans les expositions et il faut payer pour la voir. Quelle ridicule superstition ! Nous, civilisés, nous baisserions la vue en présence d'une semblable racine, tandis que les Chinois, se bousculent, se culbutent et donnent leur argent pour voir cette curiosité (traduit du Country Gentlcmen)."

Je vous demande bien pardon, bienveillants lecteurs, d'être entré dans des détails aussi tortueux, aussi délicats, mais je voulais dire tout ce que je sais de cette culture. On ne me reprochera pas d'avoir été parcimonieux de mes renseignements puisque j'ai traité cette question de la tête au trognon.

Je vous avonerai franchement, que tout en appréciant les conseils de mon ami, je ne cross pas que tous les planteurs de Ginseng aient la patience de suivre tous ces conseils dans tous leurs détails, hormis qu'ils aient la patience d'un moine ou d'un notaire. 


\section{AUX DÉBUTANTS}

Je suis bien aise de vous citer le travail intelligent d'un débutant pour vous montrer où mène l'énergie :

“ Il y a 3 ans j'ai débuté dans ma culture du Ginseng avec 350 racines d'origine sauvage de nos montagnes (Laurentides de Québec); je ne connaissais rien de cette culture mais $j$ 'ai pris des renseignements auprès des cultivateurs de Ginseng. Aujourd'hui, je suis heureux de vous dire que $j$ 'ai I 2,000 graines en stratification (janvier I907), 6,000 petites racines d'un an que je transplanterai l'automne prochain ; 4,00o graines qui lèveront le printemps prochain et 2500 graines que je conserve en pépinière pour la reproduction de la graine. Inutile de mentionner mon nom dans votre livre car je ne veux vendre ni graines ni plants que je conserve pour moi, j'espère d'avoir dans quatre ans un arpent en culture. Comme il faut à la graine 8 ans pour faire une bonne racine de commerce, je vais diviser mon arpent en 8 parties égales afin d'en avoir $1 / 8$ à vendre tous les ans ; la partie récoltée sera remplacée par du jeune plant. Je me moque de l'incrédulité de ceux qui préfèrent critiquer qu'agir. Jespère, mon clier Docteur, que vous allez vous faire le protecteur et le défenseur de cette charmante plante de Ginseng, qui sera avant longtemps pour le Canada une précieuse source de revenus."

\section{ACHA'T DES GRAINES E'T DES PLANTS}

Vous êtes sans doute bien aise de connaître le prix approxinatif des graines et des plants.

Vous pouvez vous procurer ces articles de provenance canadienne aux prix suivants :

GRAINES

$\begin{array}{rccr}100 & \text { choix } & \text { No. I } & \$ 5.00 \\ 200 & \text { “ } & \text { " } & 8.00 \\ 500 & \text { “ } & \text { " } & 15.00 \\ 1000 & \text { } & & 25.00\end{array}$

\begin{tabular}{|c|c|c|}
\hline PLA & $\begin{array}{l}\text { NTS } \\
\text { No. }\end{array}$ & $\begin{array}{l}D^{\prime} U N A N \\
I \$ I 0.00\end{array}$ \\
\hline 200 & & 16.00 \\
\hline 500 & & 30.00 \\
\hline 1000 & ، & 50.00 \\
\hline
\end{tabular}

II n'y a pas longtemps les Américains vendaient ces articles trois fois plus cher et ces graines n'avaient pas le mérite d'être acclimatées comme celles que nous pouvons nous procurer aujourd'hui dans Québec.

Les frais d'envoi sont aux charges du vendeur.

Vous pourriez obtenir ces graines ou plants à meilleur marché en concentrant ros commandes en une seule. Si 
5 voisins, par exemple, demandent au nom d'un seuI 1000 graines stratifiées, elles ne coûteront que \$2.50 du 100 au lieu de $\$ 5.00$; et les plants d'un an achetés an 1000 ne rous couteront que $\$ 5.00$ du roo au lieu de $\$$ IO.00. Voyez les bons effets de la co-opération que je prône depuis si longtemps et par laqielle on obtient toujours ume grande réduction dans les achats. Les bons effets de la co-opératiou ne s'arrêtent pas là ; étant 5 voisins qui faites de la culture de Ginseng, rous pourriez vous entr'aider les uns les autres de ros conseils dans cette industrie, et quand arrirera le temps de vendre vos produits, vous obtiendrez un meilleur prix pour la simple raison que les acheteurs de Ginseng aiment mieux acheter ce produit par grande quantité.

\section{VENTE DU GINSENG}

Défiez-vous de certains acheteurs de Ginseng, petz consciencieux qui ont intérêt à déprécier votre marcliandise pour l'obtenir à meilleur marché. Comme cette industrie est peu déreloppée, les acheteurs sont peu nom. breux, mais le jour où nous aurons à mettre sur le marché une quantité assez considérable de ce produit, je me charge, arec votre concours, d'établir une concurrence entre les acheteurs comme cela se pratique pour la vente du beurre et du fromage. Mais pour arriver à ce résultat il faut de 1'union entre les producteurs du Ginseng, et c'est pourquoi nous devons avoir tôt ou tard une association connule à peu près sous le nom suivant: Association Canadienne de Produdenrs de Ginseng, avec des marques spéciales indiquant le degré de valeur des produits. Nous anrons un entrepôt à Montréal, où nos produits seront conservés moyennant une légère commission et oì les aclieteurs pourront se renseigner sirr les quantités à vendre et où ils pourront déposer leurs soumissions d'achat. Ce sera là un excellent moyen d'établir une bonne concurrence entre les acheteurs. Ceci est encore de la coopération; la concentration daus les acluats de graines et plants comne la concentration dans la vente des racines, telle sera la clef du succès dans cette industrie.

La chose est aisée à comprendre. Un cultivateur qui se présente seul cliez l'acheteur avec quelques livres de Ginseng, est à la merci de cet aclietenr, et il faut bien qu'il accepte ses prix ou qu'il rapporte sa marchandise. Mais il n'en sera plus ainsi quand nous aurous une Association bien organisée et régulière arec un entrệồt à 
Montréal contenant plusieurs milliers de livres de balles racines de Ginseng, bien toilettées et bien empaquetées.

En attendant, je prierais tous les cultivateurs de Ginseng de m'envoyer leurs adresses postales pour les mettre au courant du prix de cette marchandise.

\section{COMMENT PARTIR UN ARPENT DE GINSFNG AVEC \$50.00}

Il volıs faut pour cela 2,000 graines stratifiées. c'est-àdire précieusement conservées depuis leur maturité par couches dans de la terre bien préparée au prix de \$25,00 le rooo. Je ne conseille pas la graine brute et je ne voudrais pas en vendre une se:ıle car il en lèverait à peine Io sur Ioo.

Ça prend is mois à une graine ponr lever. Alors les graines semées au printemps 1907, devant lever en I 908 donneront en moyenue 20 graines à l'été I 910 et 50 graines chacune l'année suivante, seconde année to,000 graines; jième 100,000 graines; tièmle année I00,000 graines.

Comme il faut is mois à la graine de Ginseng pour germer, les graines de 1910 produiront des plants au printemps de 1912 ; les graines de I9I I en produiront à celui de I9I3, celles de I9I 2 au printemps de I9I 4 et, au bout de cette période cela formera 200,000 plants en croissance, en allonant 40.000 graines pour pertes outre les récoltes de IgI 3 et de IgIt en mains qui doisent former un lot de 200,000 ; et les 2,000 plants provenant des 2,000 graines avec lesquelles vous avez commencé, qui sur le pied de 2 onces chaque donneront $83^{1 / 3}$ livres de racines sèches à $\$ 6.00$ la livre réaliseront un total de $\$ 500.00$ en argent, plus 200 ,000 plants en croissance et 200,000 graines en mains.

Où pouvez-vous retirer ailleurs un intérêt d'argent aussi éleré, qui fait à tout compter 1000 piastres pour unce piastre.

- Bienveillants lecteurs, je me mets à votre disposition pour tous autres renseignements que $j$ 'aurais pu oublier de donner, malgré ma bonne volonté et dont vous pourriez avoir besoin pour assurer le succès de votre entreprise dans la culture du Ginseng.

J'ai l'assurance de mes deux amis si discrets qui ne veulent pas que je livre leur nom à la publicité, que j'aurai à l'avenir leur généreux concours pour répondre aux 
questions qui me seront posées concernant la culture dı Ginseng.

Alors ne vous gênez pas, je me mets entièrement à votre disposition pour tous renseignements qu'il vous plaira de me demander.

Produisons beaucoup mais bien tel est mon dernier mot.

$$
\text { Dr W. GRIGNON, }
$$

Membre du Conseil d'Agriculture, SAINTE-ADELE, QUe.

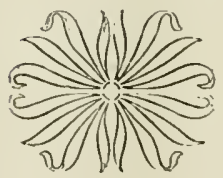




\section{TABLE DES MATIERES}

PAGFS

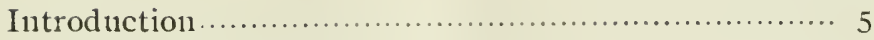

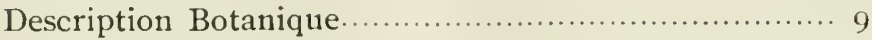

Description Populaire.................................... IO

Propriétés Médicales ...................................... IO

Histoire-Origine-Valeur ............................ I I

Marché illimité ........................................ I 2

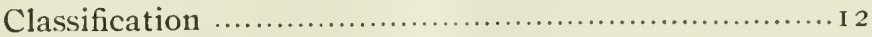

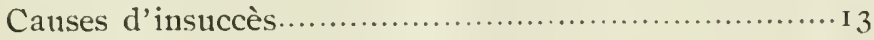

La Culture Artificielle du Ginseng ........................ I 4

Le Ginseng de la Forêt.................................... 4

Nature du sol-Où cultiver le Ginseng................. I 5

Préparation du sol .......................................... I 5

Ombrage ................................................... 6

Lits ou couches........................................... 7

Plantation des Graines................................... IS

Préparation du sol pour lit permanent................... I9

Après la plantation des graines.......................... I 9

Contre la gelée............................................. 9

Plantation des graines à demeure perpétuelle .............20

Plantation des racines ou plants........................20

Croissance du Ginseng...................................22

Volailles, chats, chiens et voleurs.......................22

Quelques soins de culture ...............................23

Un fait singulier-Production des graines................23

Cueillette des graines.......................................24

Stratification des graines .....................................24

Premier procédé de stratification.........................24

Deuxième procédé de stratification.......................25

Culture du Ginseng sous bois.............................26

L'âge du Ginseng ....................................... 8 
Récolte dı Ginseng-L'arrachage $\ldots \ldots \ldots \ldots \ldots \ldots \ldots \ldots \ldots . \ldots$

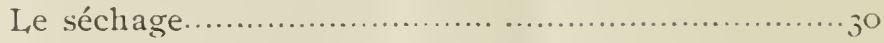

Trillage des racines et empaquetage ....................... 32

Ennemis du Ginseng ....................................... 32

Petites remarques........................................ 32

La culture du Ginseng dans le Manitoba et le

Nord-Ouest ...................................... 33

Engrais spécial......................................... $3+$

Comment obtenir des racines à forme humaine............ 34

Un grand secret dirulgué............................... $3 t$

Aux débutants.......................................... 39

Achats des graines et des plants.......................... 39

Vente du Ginseng....................................... to

Comment partir un arpent de Ginseng avec $\$ 50 \ldots . . . . .4$ I

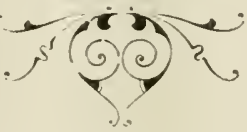




\section{INDEX DES GRAVURES}

PAGTiS

Tige de Ginseng...............................(Fig. I) I

Tige et racine de Ginseng.....................(Fig. 2) 3

Panneau mobile de $4 \times 8$ pieds............... (Fig. 3) 17

Jardin de Ginseng............................(Fig. 4) 2 I

Culture du Ginseng sous bois..................(Fig. 5) 27

Racines de Ginseng à l'état frais provenant

de plants cultivés........................(Fig. 6) 29

Racine de 5 ans, bonne pour le marché.... (Fig. 7) 3I

Racine de Ginseng desséchée...................(Fig. 8) 33

Racine de Ginseng à forme humaine..........(Fig. 9) 35

Jardin de Ginseng............................. (Fig. 10) 37

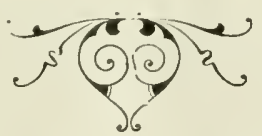






La Bibliothèque Université d'Ottawa Echéance
The Library University of Ottawa Date Due

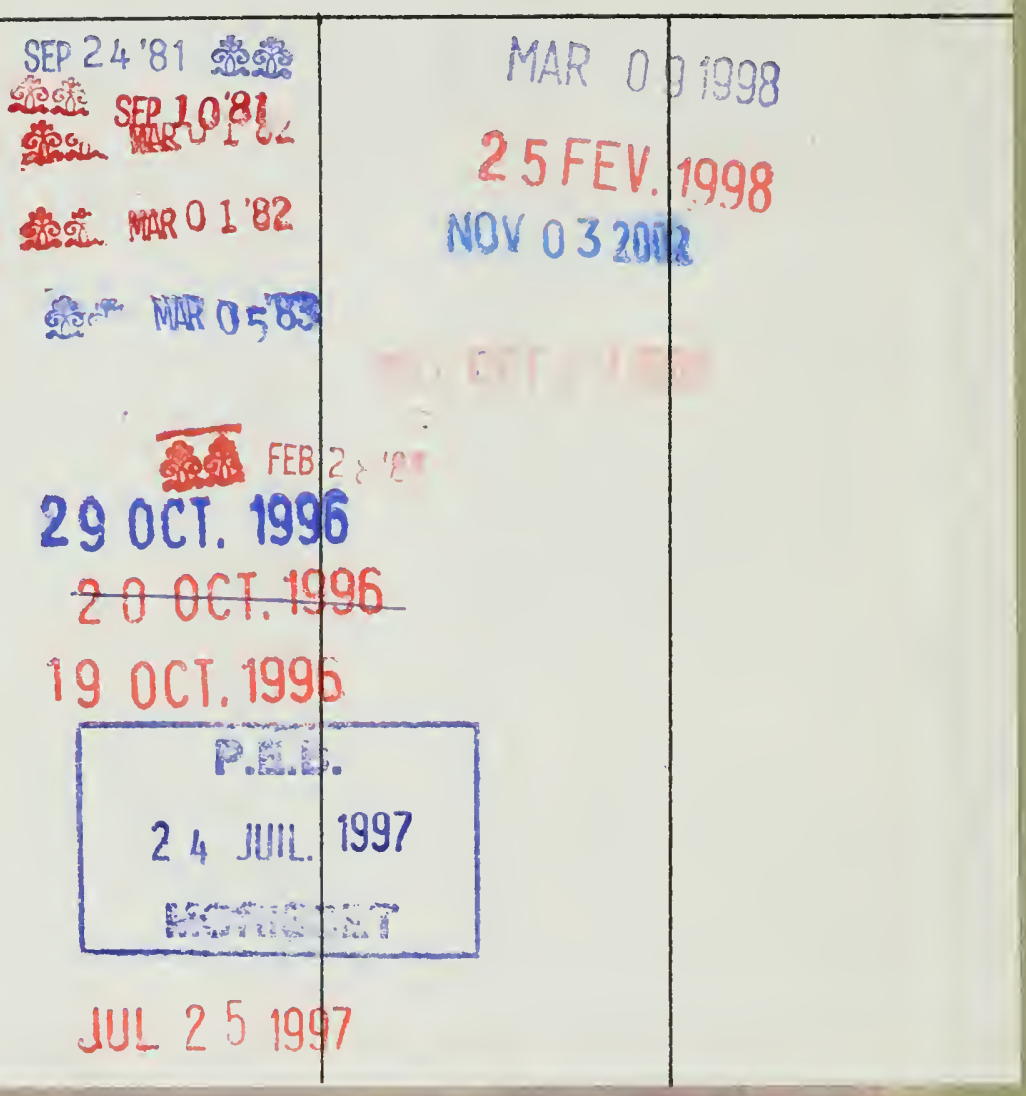




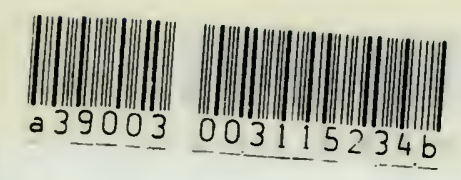
$\begin{array}{llllllllllllll}S & B & 2 & 9 & 5 & 6 & 5 & 6 & 7 & 1 & 9 & 0 & 7\end{array}$
G R I G N O N T UILFRI D
C ULTURE DU G IN S ENG 
